\title{
Quercetin nanoparticle complex attenuated diabetic nephropathy via regulating the expression level of ICAM-I on endothelium
}

This article was published in the following Dove Press journal:

International Journal of Nanomedicine

24 October 2017

Number of times this article has been viewed

\author{
Fei Tong ${ }^{1,2}$ \\ Suhuan Liu' \\ Bing Yan' \\ Xuejun $\mathrm{Li}^{\prime}$ \\ Shiwei Ruan ${ }^{3}$ \\ Shuyu Yang' \\ 'Department of Endocrinology \\ and Diabetes, The First Affiliated \\ Hospital, Xiamen University, Xiamen, \\ ${ }^{2}$ Department of Pathology and \\ Pathophysiology, Provincial Key \\ Discipline of Pharmacology, Jiaxing \\ University Medical College, Jiaxing. \\ Zhejiang, ${ }^{3}$ Academy of Integrative \\ Medicine, Fujian University of \\ Traditional Chinese Medicine, Fuzhou, \\ People's Republic of China
}

\begin{abstract}
The purpose of the study was to reveal the therapeutic effect of quercetin (QUE) nanoparticle complex on diabetic nephropathy (DN) by regulating the expression of intercellular adhesion molecular-1 (ICAM-1) on endothelium as compared to free QUE. QUE $10 \mathrm{mg} / \mathrm{kg}$ as a single abdominal subcutaneous injection daily for 8 weeks continuously in diabetic rats and $10 \mathrm{mg} / \mathrm{kg}$ QUE nanoparticle complex as a single abdominal subcutaneous injection every 5 days, continuously administered for 8 weeks to diabetic rats. Blood and left kidneys were collected; pathological change of kidney, renal function, oxidative stress level, blood glucose level, serum lipid, urine protein, and albumin/creatinine ratio were measured; and neutrophil adhesion, ICAM-1 expression, and CD11 $\mathrm{b}^{+}$cells infiltration were observed. Both QUE and QUE nanoparticle complex preconditioning ameliorated the pathological damage of kidney and improved renal function, alleviated renal oxidative stress injury, restricted inflammatory cells infiltration, and downregulated the ICAM-1 expression as compared to DN group, while QUE nanoparticle complex significantly alleviated this effect.
\end{abstract}

Keywords: nanoparticle complex, quercetin, DN, ICAM-1, CD11b ${ }^{+}$, endothelium

\section{Introduction}

Approximately one-third of long-standing diabetes leads to nephropathy. ${ }^{1,2}$ Diabetic nephropathy $(\mathrm{DN})$ is a life-threatening complication in diabetes mellitus and is the biggest single cause of end-stage kidney diseases. ${ }^{3-7}$ The mechanism involved in DN ranges from oxidative stress, derangement of glucose metabolism, and the activation of abundant inflammatory mediators and cell factors to cellular death. ${ }^{8-10}$ In particular, constant hyperglycemia is the proegumenal cause of initiation, promotion, and sustentation of DN. ${ }^{11}$ Quercetin (QUE) belongs to plant flavonoid and possesses potent anti-oxidant properties in vitro, and recent data have shown that QUE may have anti-cancer and anti-inflammatory functions in vivo. ${ }^{12}$ In the current study, QUE can attenuate $\mathrm{DN}$ and is an effective treatment for $\mathrm{DN}$; the result is consistent with previous documents. ${ }^{12,13}$ However, poor water solubility, low bioavailability, and short half-life of QUE restrict its use in vivo. ${ }^{14}$ Recent researches affirm that drug delivery via nanoparticles can improve efficacy with decreasing side effects. ${ }^{15}$ In this regard, poly(ethylene glycol)-block-(poly(ethylenediamine l-glutamate)-graft-poly( $\varepsilon$-benzyloxycarbonyl1-lysine)) (PEG- $b$-(PELG- $g$-PZLL)) is synthesized and QUE/PEG- $b$-(PELG- $g$-PZLL) (QUE/P) nanoparticle complex is measured in vitro and vivo.

Several researches suggest that endothelial cells (ECs) are sensitive to DN and they might be a critical mediator of DN. ${ }^{16,17}$ Under normal condition, ECs offer a 
protective barrier between lumen and vascular smooth muscle of blood vessel, and the ECs are momentous players in modulating blood flow, neutrophil, complement activation, and renal function. ${ }^{18-21}$ The EC surface proteins involved in DN are known as cell adhesion molecules (CAMs), which are distributed at various time courses of activations and expressions. ${ }^{22,23}$ The original interactions between polymorphonuclear $(\mathrm{PMN})$ cells and ECs are mediated via CAM expressed on the EC surface. ${ }^{24}$ This CAM-mediated interaction leads to the rolling of PMNs along vessel walls and upregulation of intercellular adhesion molecule-1 (ICAM-1) on the PMNs. ${ }^{23,24}$ As a result, CD $11 b^{+}$associates with its counter receptors on ECs, mainly ICAM-1, leading to their firm adhesion and transmigration by vascular wall..$^{25,26}$ Substantial evidence indicates that expression of adhesion molecules via glomerular ECs is increased following DN. ${ }^{17,27,28}$ Therefore, understanding discovery of ECs will improve the effective therapies, which can be applied in $\mathrm{DN}$ procedure.

QUE is a representative flavonoid that alleviates DN. ${ }^{29}$ Many documents have proved that treatment with QUE remarkably ameliorates renal dysfunction and oxidative stress injury in DN. ${ }^{3}$ In addition, QUE acts as an anti-inflammatory factor (such as ICAM-1) and modulates CD11b ${ }^{+}$, which may have implications for strategies attenuating endothelial dysfunction. ${ }^{30-32}$ In this study, QUE regulates endothelial expression of ICAM-1 and attenuates inflammatory cell infiltration $\left(\mathrm{CD} 11 \mathrm{~b}^{+}\right)$, and ameliorates glucose metabolism and lipid metabolism disorder in DN. As is well known, the in vivo solubility of QUE is very low and circulation time is extremely short. ${ }^{14}$ Here, a PEG- $b$-(PELG- $g$-PZLL) carrier (Scheme 1; Figure $1 \mathrm{G}$ ) as a potential QUE nanoparticle (Figure $1 \mathrm{G}$ ) is reported. The PEG- $b$-(PELG- $g$-PZLL) and QUE form a compound via hydrophobic interaction (Figure 1G). The loaded QUE confirms stable and sustained

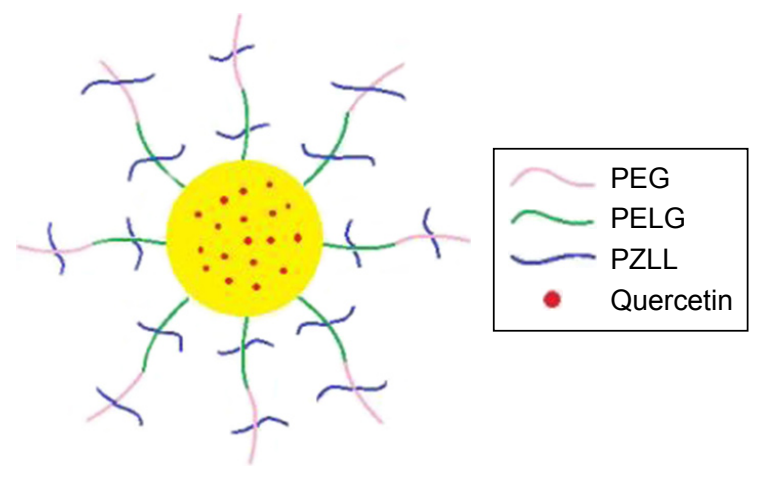

Scheme I The structure of quercetin/PEG-b-(PELG-g-PZLL). Abbreviation: PEG-b-(PELG-g-PZLL), poly(ethylene glycol)-b-(poly(ethylenediamine I-glutamate)-g-poly( $\varepsilon$-benzyloxycarbonyl-I-lysine)). release, which can develop the study on the protective effect of QUE. QUE encapsulation and in vitro release are affirmed. In vivo study is implemented by the hypodermic injection of QUE/P nanoparticle to DN in diabetic rats, followed by the measurement of blood urine nitrogen (BUN), serum creatinine (Scr), blood glucose, and serum lipid; detections of superoxide dismutase (SOD) activity and methane dicarboxylic aldehyde content in renal tissues; inspection of urine protein and albumin/creatinine ratio; and finally neutrophil adhesion, ICAM-1 expression, and CD11 $\mathrm{b}^{+}$cells infiltration.

\section{Materials and methods Materials}

PEG-NH ${ }_{2}$ (molecular weight $=5 \mathrm{kDa}$ ), BLG, and $\varepsilon$-benzyloxycarbonyl-1-lysine were purchased from Aladdin (Shanghai, People's Republic of China); QUE was purchased from Shanghai excellent Biotechnology Co., Ltd; HeLa cell was purchased from Shanghai Hao Ran Biological Technology Co., Ltd; human umbilical vein endothelial cells (HUVECs) were purchased from Shanghai Bioleaf Biotech Co., Ltd; streptozotocin and other reagents were purchased from Nanjing Built Biological Technology Co., Ltd and Sigma.

\section{Methods}

\section{Synthesis of PEG-b-(PELG-g-PZLL)}

Synthesis of PEG- $b$-(PELG- $g$-PZLL) was elaborated in our previous works. ${ }^{33}$

\section{Cytotoxicity evaluation of PEG-b-(PELG-g-PZLL)}

Cytotoxicity evaluation of PEG- $b$-(PELG- $g$-PZLL) mainly referred to our previous works. ${ }^{33}$

\section{Loading of QUE through PEG-b-(PELG-g-PZLL)}

To investigate the encapsulation of QUE through PEG- $b$ (PELG-g-PZLL), a fixed amount of QUE $(5 \mathrm{mg} / \mathrm{mL})$ in PBS was associated with PEG- $b$-(PELG- $g$-PZLL) in PBS and then dialyzed via dialysis bag ( $\mathrm{MWCO}=7 \mathrm{kDa})$. The PEG- $b$-(PELG- $g$-PZLL)-encapsulated QUE was measured by high-performance liquid chromatography (HPLC) and transmission electron microscopy (TEM).

\section{In vitro release}

QUE release from PEG- $b$-(PELG- $g$-PZLL) was assessed via dialysis ( $\mathrm{MWCO}=7 \mathrm{kDa}$ ) at $37^{\circ} \mathrm{C}$ with $5 \mathrm{~mL}$ of QUE/P compound against $80 \mathrm{~mL}$ of $0.02 \mathrm{~mol} / \mathrm{L} \mathrm{PB}$. At $(0.02-5)$ day time interval, a fixed amount of release medium was extracted and replenished with a proper amount of fresh release medium. The quantity of released QUE remaining in the dialysis bag was assessed via HPLC. The free QUE 
release in the absence of polymeric compound was also implemented as a control.

\section{Animals}

Male Sprague Dawley rats (170-230 g) were obtained from Jiaxing University, Medical College, Jiaxing, People's Republic of China. The procedures and care of the Sprague Dawley rats were authorized by the Institutional Ethics Committee of
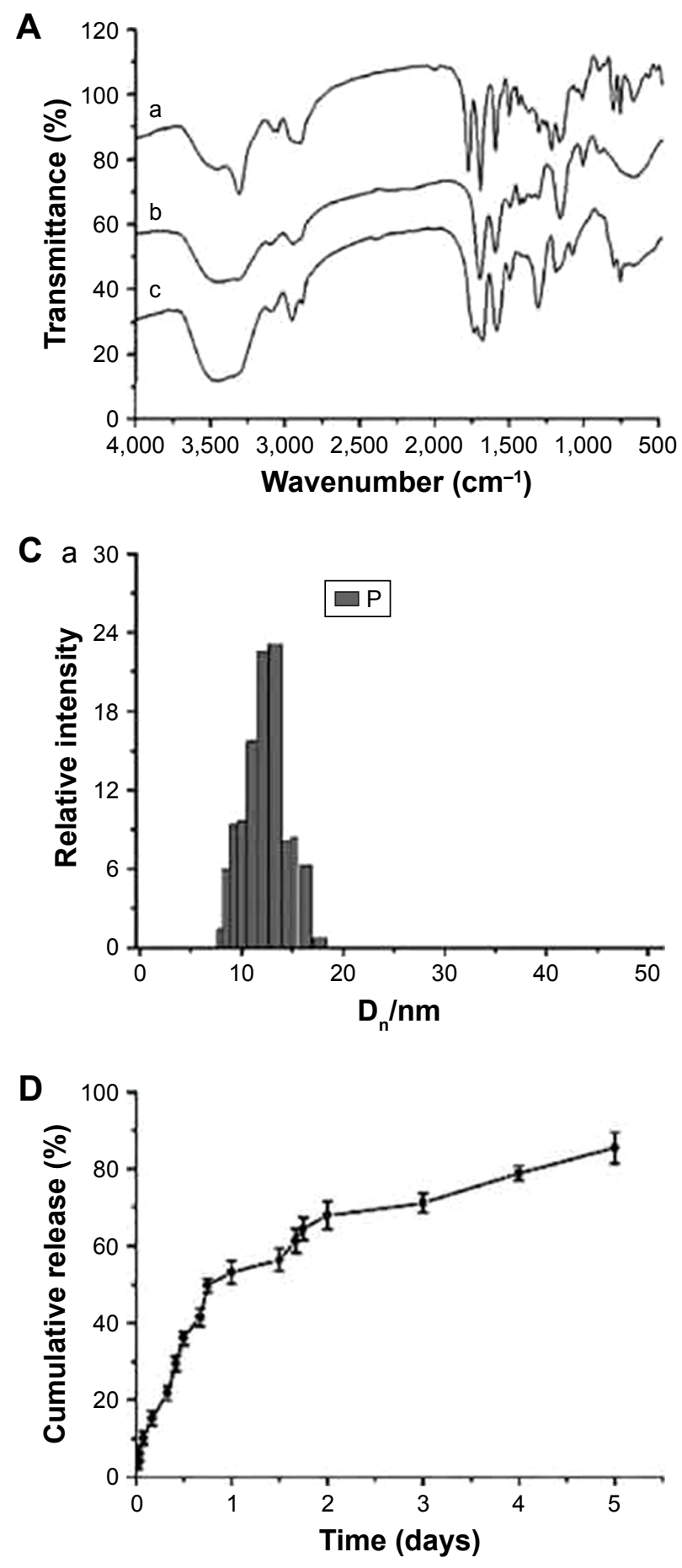

Jiaxing University, Medical College, Jiaxing, People's Republic of China. The expedition conformed to the guide for the care and use of laboratory animal published by the US National Institutes of Health (NIH Publication updated in 2011).

\section{Blood QUE concentration assessment}

Sprague Dawley rats were administrated a dose of $10 \mathrm{mg} / \mathrm{kg}$ QUE or QUE/P via abdominal subcutaneous injection.

B
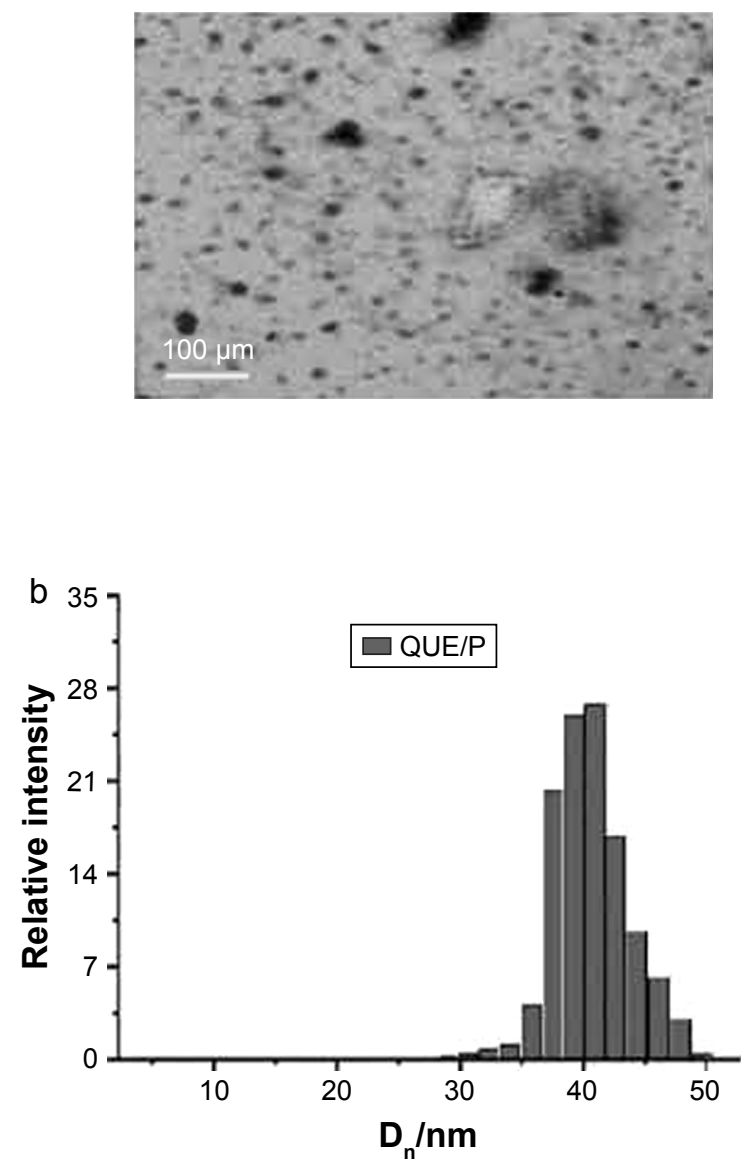

E

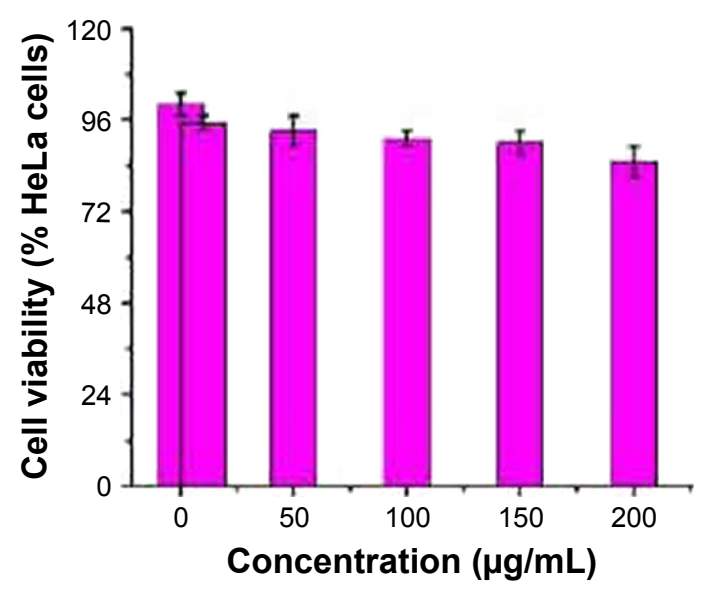

Figure I (Continued) 


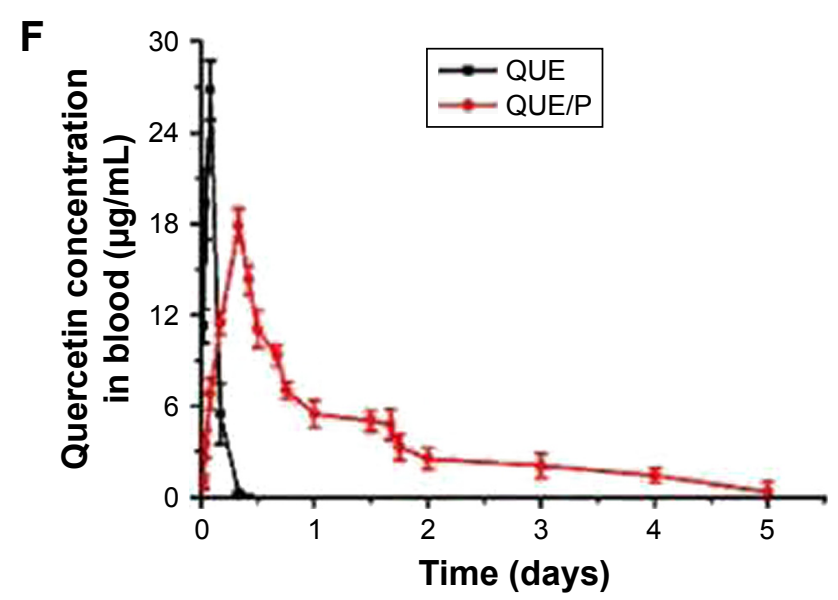

G

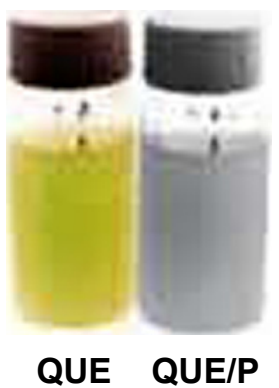

Figure I Characterization of PEG-b-(PELG-g-PZLL) and QUE/P.

Notes: (A) a, PEG-b-PBLG; b, PEG-b-PELG; c, PEG-b-(PELG-G-PZLL). FTIS of PEG-b-(PELG-g-PZLL); (B) TEM image of QUE/P; (C) a, particle size of P; b, particle size of QUE/P; (D) cumulative release profile of QUE/P; (E) cellular viability of HeLa cells cultured with different concentrations of PEG-b-(PELG-g-PZLL); (F) blood concentration of free QUE and QUE from QUE/P; (G) solution color of QUE and QUE/P.

Abbreviations: PEG-b-(PELG-g-PZLL), poly(ethylene glycol)-b-(poly(ethylenediamine l-glutamate)-g-poly(E-benzyloxycarbonyl-I-lysine)); QUE/P, quercetin/PEG-b-(PELG-gPZLL); FTIS, Fourier transform infrared spectroscopy; TEM, transmission electron microscopy.

A volume of $0.2 \mathrm{~mL}$ blood was extracted at a fixed time interval from aorta abdominalis and then separated promptly via centrifugation $(12,000 \times g$ for $20 \mathrm{~min})$, and immediately stored at $-80^{\circ} \mathrm{C}$ for the following analyses. The concentrations of QUE and QUE/P were evaluated via HPLC following the previous reports. ${ }^{34}$

\section{Distribution of QUE/P compound in Sprague Dawley rats}

Sprague Dawley male rats were administrated a dose of $10 \mathrm{mg} / \mathrm{kg}$ QUE/P via abdominal subcutaneous injection. To extract left kidneys into test tubes, miscible liquids including $0.2 \mathrm{~mL} 60 \%$ perchloric acid and $0.2 \mathrm{~mL} 30 \%$ hydrogen peroxide were added. The sample was kept in a $80^{\circ} \mathrm{C}$ water bath for $50 \mathrm{~min}$ and then color of the sample changed to faint yellow. To extract $0.2 \mathrm{~mL}$ of tissue liquid, $1 \mathrm{~mL}$ of scintillation solution and $3 \mathrm{~mL}$ of absolute ethyl alcohol were added, and then radioactivity of the left kidney was measured via TRI-CARB2900 TR liquid scintillation counter (PACKARB) following previous methods. ${ }^{35}$

\section{Diabetic animal procedure}

Male Sprague Dawley rats were administrated a high-fat diet (fat content 40\%) for 10 weeks and then streptozotocin was injected only once at a dose of $35 \mathrm{mg} / \mathrm{kg}$ through abdomina. After 3 days, diabetes was evaluated by checking blood glucose content using glucose oxidase-peroxidase (GOD-POD) methods. ${ }^{36}$ Animals with blood glucose content $>16.7 \mathrm{mmol} / \mathrm{L}$ were used in the study.

\section{Therapeutic assessment of QUE/P compound in diabetic rats}

Thirty diabetic rats were randomly assigned to three groups ( $\mathrm{n}=10$, each group): 1) control group; 2) QUE group: $10 \mathrm{mg} / \mathrm{kg}$ as a single abdominal subcutaneous injection; 3) QUE/P group: $10 \mathrm{mg} / \mathrm{kg}$ as a single abdominal subcutaneous injection. At a fixed time, blood glucose contents were checked by GOD-POD ways. ${ }^{36}$

\section{QUE/P suppresses neutrophil adhesion in vivo}

To study the functional relevance of QUE/P, we checked the effect of QUE/P on leukocyte adhesion to ECs. The detailed process mainly referred to previous documents. ${ }^{25}$ To measure the change, we added QUE and QUE/P in HUVECs, and treated by tumor necrosis factor- $\alpha$ (TNF- $\alpha$ ), added carboxyfluorescein diacetate succinimidyl ester-labeled acute promyelocytic leukemia (HL-60) leukocytes, washed the mixtures, and checked leukocyte binding to the ECs. Neutrophil adhesion in vivo was observed by immunofluorescence microscopy method.

\section{Therapeutic assessment of QUE/P compound in DN}

Eight normal Sprague Dawley rats and 24 diabetic rats were assigned to four groups ( $n=8$, each group): 1) Sham group: normal Sprague Dawley rats were administrated a standard diet; 2) DN group: equal volume of normal saline was subcutaneously injected for 8 weeks in diabetic rats; 3) QUE group: $10 \mathrm{mg} / \mathrm{kg}$ as a single abdominal subcutaneous 
injection daily for 8 weeks continually in diabetic rats; and 4) QUE/P group: $10 \mathrm{mg} / \mathrm{kg}$ as a single abdominal subcutaneous injection every 5 days, continually injected for 8 weeks to diabetic rats. At a fixed time, blood and left kidneys were collected. Renal pathological damage, BUN, Scr, SOD: the kidneys were collected and the blood was purged drastically, homogenized $(100 \mathrm{mg})$, and centrifuged at $3,600 \times g$ for $20 \mathrm{~min}$ to gain the liquid supernatant. SOD activity was checked using xanthine oxidase method. The absorbances were checked at $550 \mathrm{~nm}$. Lipid peroxide contents were shown by " $U$ " of SOD/ mg protein in tissues, malonyldialdehyde (MDA, the kidneys were collected and the blood was purged drastically, homogenized (100 mg), and centrifuged at 3,600× $g$ for $20 \mathrm{~min}$ to gain the liquid supernatant. MDA level was measured through thiobarbituric acid method. The absorbances were checked at $532 \mathrm{~nm}$. Lipid peroxide contents are shown by "nmol" of $\mathrm{MDA} / \mathrm{mg}$ protein in tissues.), serum lipid, urine protein (after 8 weeks, 24 h urine was collected with a metabolic cage for diabetic rats and urine protein was measured by Hitachi 7170 automatic biochemical analyzer.), albumin/creatinine ratio (after 8 weeks, 24-h urine was collected with a metabolic cage for diabetic rats, and albumin and creatinine were measured by Hitachi 7170 automatic biochemical analyzer, then albumin/ creatinine ratio was calculated.), $\mathrm{CD} 11 \mathrm{~b}^{+}$cells infiltration (referred to previous literature ${ }^{25}$ ), and expression of ICAM-1 (referred to previous literature ${ }^{25}$ ) were evaluated.

\section{Statistical analyses}

The analysis was actualized via SPSS. Data were expressed as the mean \pm standard deviation. Statistical analysis was actualized by unpaired Student's $t$-tests or ANOVA. Value of $p<0.01$ was considered statistically remarkable.

\section{Results \\ Synthesis and characterization of PEG-b-(PELG-g-PZLL)}

The PEG- $b$-(PELG- $g$-PZLL) contained a PEG block and a brush-like PZLL block (Figures S1 and S2); they were characterized via Fourier transform infrared spectroscopy, as depicted in Figure 1A.

\section{Cellular viability assessment}

The assessment of cell toxicity from PEG- $b$-(PELG- $g$ PZLL) on HeLa cells was measured in 24-h culture and the result is shown in Figure 1E. PEG- $b$-(PELG- $g$-PZLL) maintained low cell toxicity even below a concentration as high as $200 \mu \mathrm{g} / \mathrm{mL}$.

\section{Encapsulation capacity of QUE in PEG-b-(PELG-g-PZLL)}

QUE was efficiently encapsulated by PEG- $b$-(PELG- $g$ PZLL) at physiological $\mathrm{pH}$ via hydrophobic interaction. To add QUE in PEG- $b$-(PELG- $g$-PZLL) (mass ratio $=1: 5$ ) and dialyze against PB solution. The dialysis of free QUE as a control was also actualized at the same condition. To decide the encapsulation of QUE in PEG- $b$-(PELG-g-PZLL), the quantity of QUE was measured via HPLC. The encapsulation of QUE was found to be $53.2 \%$, as depicted in Table 1.

\section{Characterization assessment of QUE/P compound}

The QUE/P compound was evaluated via TEM. The image of TEM is shown in Figure 1B. The QUE/P compound displayed an orbicular structure and the diameter was $64 \mathrm{~nm}$ (Table 1). The QUE/P compound was further characterized by a granulometer. The average particle size distributions of PEG- $b$-(PELG- $g$-PZLL) and QUE/P are evaluated in Figure $1 \mathrm{C}(\mathrm{a}$ and $\mathrm{b})$ and Table 1 . The average diameters of PEG- $b$-(PELG- $g$-PZLL) and QUE/P were about 9 and $32 \mathrm{~nm}$, respectively.

\section{In vitro release of QUE}

The QUE release from PEG- $b$-(PELG- $g$-PZLL) was evaluated via dialysis method $(\mathrm{MWCO}=7 \mathrm{kDa})$ at $37^{\circ} \mathrm{C}$, with $5 \mathrm{~mL}$ of QUE/P against a PB solution of $0.02 \mathrm{~mol} / \mathrm{L}$ (physiological condition). The release curve of QUE/P is described in Figure 1D. After 4 h, 15.23\% of QUE was released from QUE/P, showing the beginning of a burst release of QUE. About $71.15 \%$ of QUE was released after 3 days and $85.43 \%$ after 5 days, showing biphase release profile from QUE/P.

\section{Serum QUE content}

The contents of QUE in serum of Sprague Dawley rats following a single subcutaneous injection in QUE group at a dose of $10 \mathrm{mg} / \mathrm{kg}$ rapidly attained $\mathrm{Cmax}$ of $26.78 \mu \mathrm{g} / \mathrm{mL}$ at

Table I Molecular weight, PDI, TEM, particle size, and QUEloading capacity of $P$

\begin{tabular}{lllllll}
\hline Sample & $\begin{array}{l}\text { Mn (kDa)/ } \\
\text { 'H NMR }\end{array}$ & $\begin{array}{l}\text { Mn (kDa)/ } \\
\text { GPC }\end{array}$ & $\begin{array}{l}\text { PDI } \\
(\mathbf{n m})\end{array}$ & $\begin{array}{l}\text { Particle } \\
\text { size } \\
(\mathbf{n m})\end{array}$ & $\begin{array}{l}\text { Loading } \\
\text { capacity } \\
(\%)\end{array}$ \\
\hline P & 37.4 & 26.1 & I.24 & NA & 9 & NA \\
QUE/P & NA & NA & NA & 64 & 32 & 53.2 \\
\hline
\end{tabular}

Abbreviations: TEM, transmission electron microscopy; QUE, quercetin; $\mathrm{P}$, poly(ethylene glycol)-b-(poly(ethylenediamine I-glutamate)-g-poly( $\varepsilon$-benzyloxy carbonyl-I-lysine)); Mn, number-average molecular weight; 'H NMR, 'H-nuclear magnetic resonance; GPC, gel permeation chromatograms; PDI, polydispersity index; NA, not applicable. 
Tmax of $2 \mathrm{~h}$, and decreased to baseline content within $10 \mathrm{~h}$ of administration. The serum content of Sprague Dawley rats following a single subcutaneous injection in QUE/P group at a dose of $10 \mathrm{mg} / \mathrm{kg}$ attained Cmax of $17.85 \mu \mathrm{g} / \mathrm{mL}$ at Tmax of $8 \mathrm{~h}$, and decreased to baseline content within 5 days of administration. The results affirmed that the release of QUE from QUE/P group was substantially sustained compared to QUE group (Figure 1F).

\section{In vivo distribution assessment}

The disintegrations per minute of kidney ranged from $89 \pm 23$ to $1,875 \pm 34$ within $0.05-5$ days through QUE/P of administration. The result affirmed that QUE/P could be metabolized through the kidneys (Figure 2).

\section{Histopathologic evaluation}

Light microscopy images of kidney sections are evaluated in Figure 3. Glomerular volume increase and swelling, tubulointerstitial fibrosis, infiltration of local lymphocytes in the renal cortex, and basement membrane hyperplasia were observed in histological specimens from DN group but were absent in Sham group (Figure 3A and B). Histological changes were reduced in QUE and QUE/P groups (Figure 3A and $\mathrm{B}$ ) compared to $\mathrm{DN}$ group. Histological changes were remarkably reduced in QUE/P group (Figure 3A and B) compared to DN group. Gross appearance of kidney is evaluated in Figure 3C. Glomerular volume increase and swelling were observed through naked eye examination in DN group but Sham group was generally normal (Figure 3C). Naked eye examination was reduced in QUE and QUE/P groups (Figure 3C) compared to DN group. Naked eye examination was remarkably reduced in QUE/P group (Figure 3C) compared to DN group.

\section{Blood glucose content}

To evaluate the blood glucose contents in a fixed time for diabetic rats administered QUE and QUE/P, and compared with control group, the result showed that diabetic rats injected with QUE maintained blood glucose contents in normal change for about $8 \mathrm{~h}$, after which glycemia slowly augmented. By contrast, QUE/P compound decreased blood glucose contents to $5.1 \mathrm{mmol} / \mathrm{L}$ at $2 \mathrm{~h}$ after administration. Over the following 5 days, blood glucose contents increased to $4.4 \mathrm{mmol} / \mathrm{L}$ and were then maintained at about 4.1-6.2 $\mathrm{mmol} / \mathrm{L}$ for 5 days (Figure 4A).

\section{BUN and Scr contents}

Level of BUN was evaluated in DN group (Figure 4B), and was found to be higher in DN group than in Sham group $(p<0.01$; BUN: Sham group $6.23 \pm 1.13 \mathrm{mmol} / \mathrm{L}, \mathrm{DN}$ group $54.37 \pm 3.79 \mathrm{mmol} / \mathrm{L})$. Administration of QUE reduced BUN $(41.05 \pm 3.38 \mathrm{mmol} / \mathrm{L})$ compared with BUN in DN group $(p<0.01)$. Administration of $\mathrm{QUE} / \mathrm{P}$ remarkably reduced BUN $(23.18 \pm 2.17 \mathrm{mmol} / \mathrm{L})$ compared with BUN in DN group $(p<0.01)$.

Level of Scr was evaluated in DN group (Figure 4C), and was found to be higher in DN group than in Sham group $(p<0.01$; Scr: Sham group 45.26 $\pm 5.78 \mu \mathrm{mol} / \mathrm{L}$, DN group $289.16 \pm 11.27 \mu \mathrm{mol} / \mathrm{L})$. Administration of QUE reduced Scr $(213.56 \pm 9.37 \mu \mathrm{mol} / \mathrm{L})$ compared with Scr in DN group $(p<0.01)$. Administration of QUE/P remarkably reduced Scr $(178.93 \pm 8.03 \mu \mathrm{mol} / \mathrm{L})$ compared with Scr in DN group $(p<0.01)$.
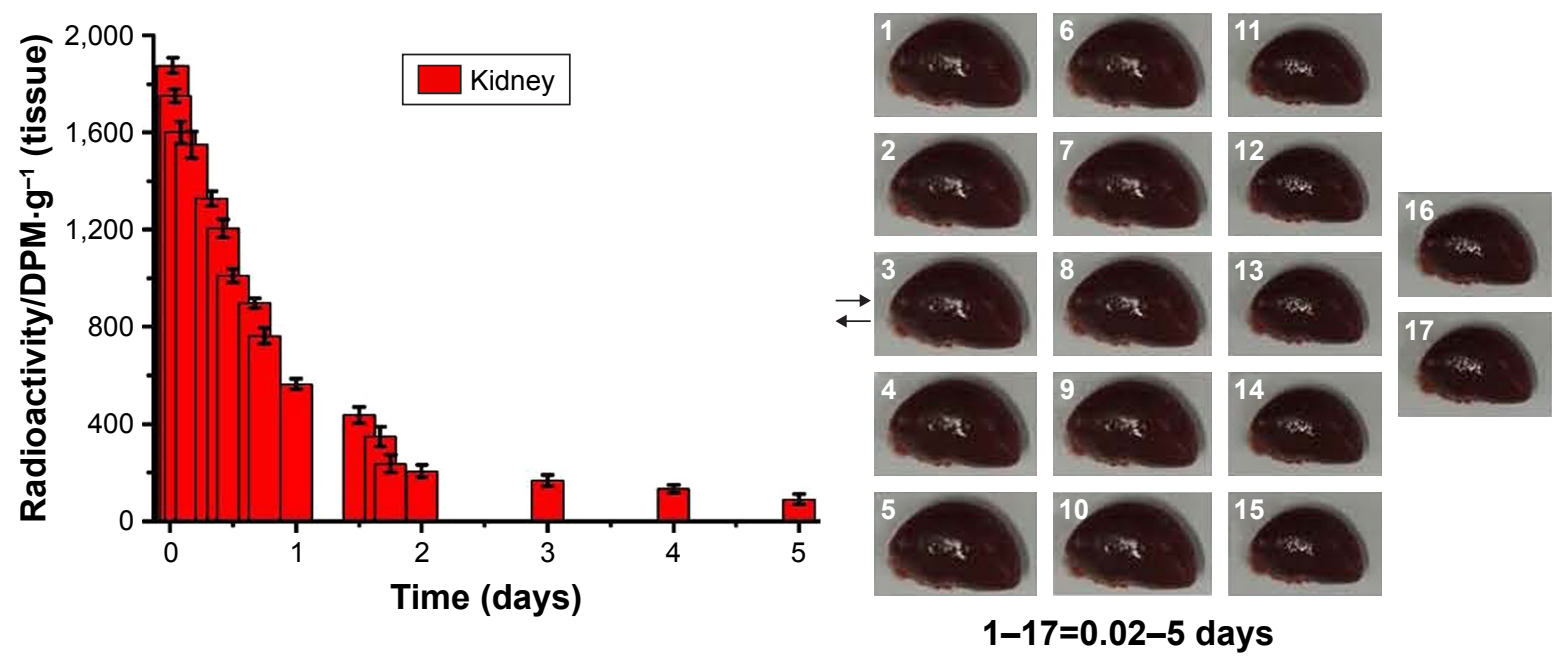

Figure 2 The distribution of quercetin/PEG-b-(PELG-g-PZLL) compound in rats.

Note: The distribution of quercetin/PEG-b-(PELG-g-PZLL) in rats and results expressed as mean \pm standard deviation.

Abbreviations: PEG-b-(PELG-g-PZLL), poly(ethylene glycol)-b-(poly(ethylenediamine l-glutamate)-g-poly(E-benzyloxycarbonyl-I-lysine)); DPM, disintegrations per minute. 


\section{A}

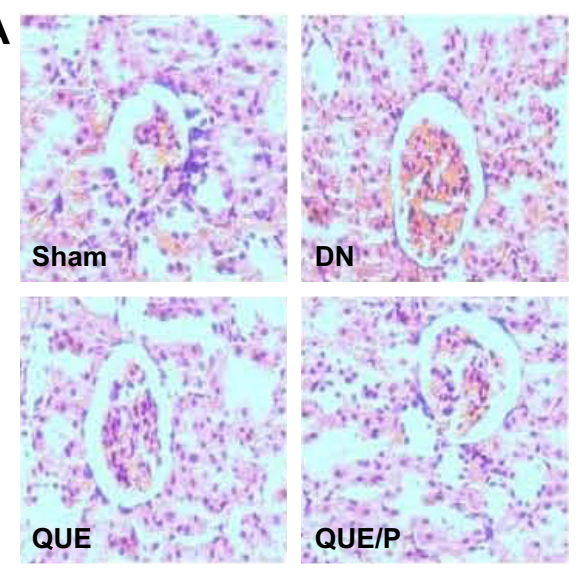

B

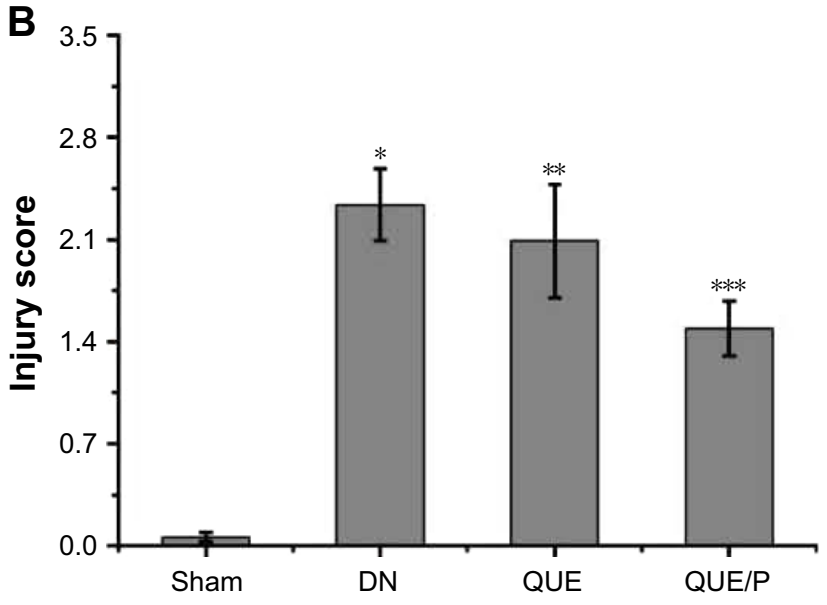

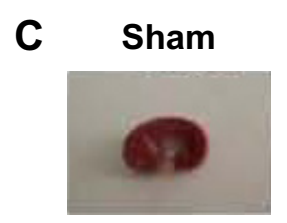

DN

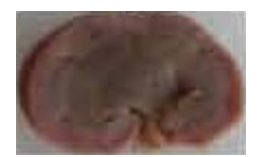

QUE

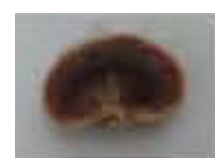

QUE/P

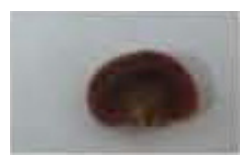

Figure 3 Histopathologic assessment of kidney damage.

Notes: Light microscope images $(\times 400)$ in Sham group, DN group, QUE group, QUE/P group, respectively $($ A); quantitative injury scores, expressed as mean \pm SD, are shown in (B); gross appearance in Sham group, DN group, QUE group, QUE/P group, respectively (C). A remarkable augment relative to Sham group is denoted by “*” $(p<0.0 \mathrm{I})$, a remarkable decrease relative to DN group is denoted by “*** $(p<0.0 \mathrm{I})$, and a remarkable decrease relative to DN group is denoted by “****" ( $<<0.0 \mathrm{I})$. Abbreviations: DN, diabetic nephropathy; QUE/P, quercetin/poly(ethylene glycol)-b-(poly(ethylenediamine l-glutamate)-g-poly( $\varepsilon$-benzyloxycarbonyl-I-lysine)); SD, standard deviation.

A
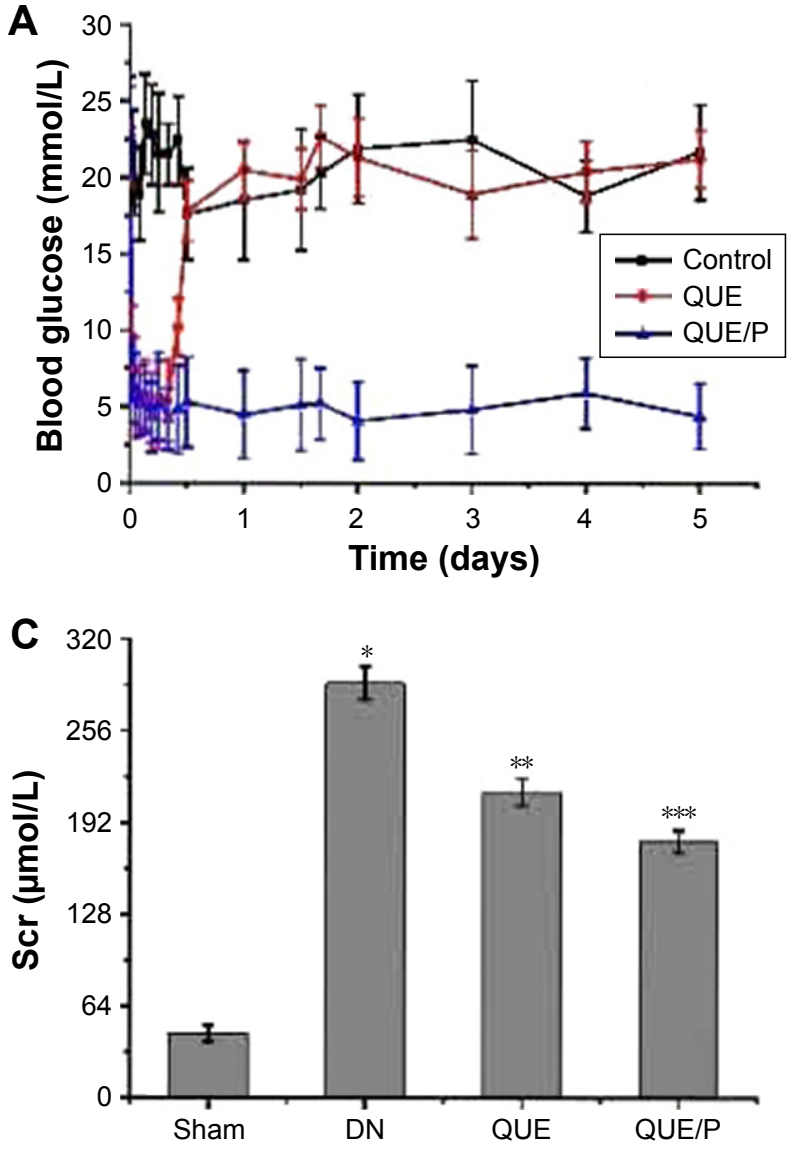

B

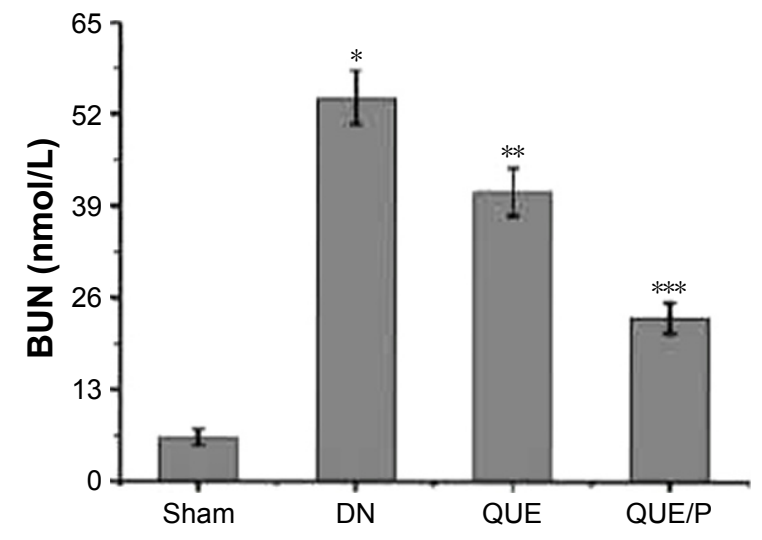

D

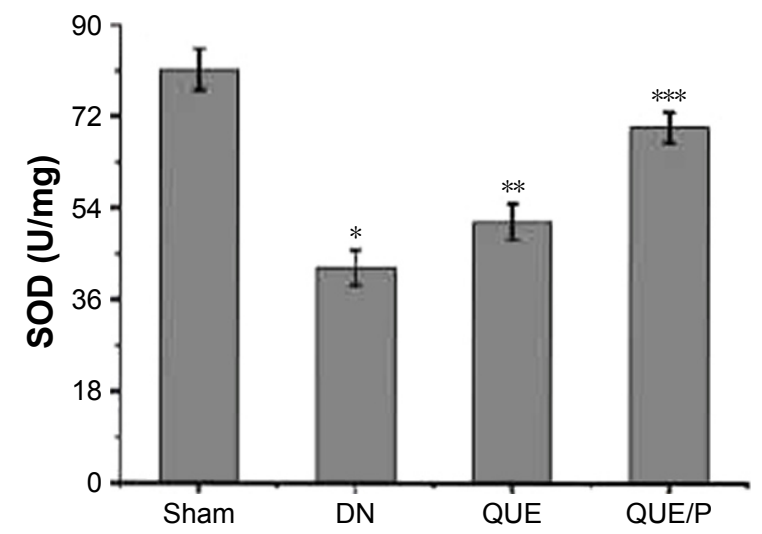

Figure 4 (Continued) 

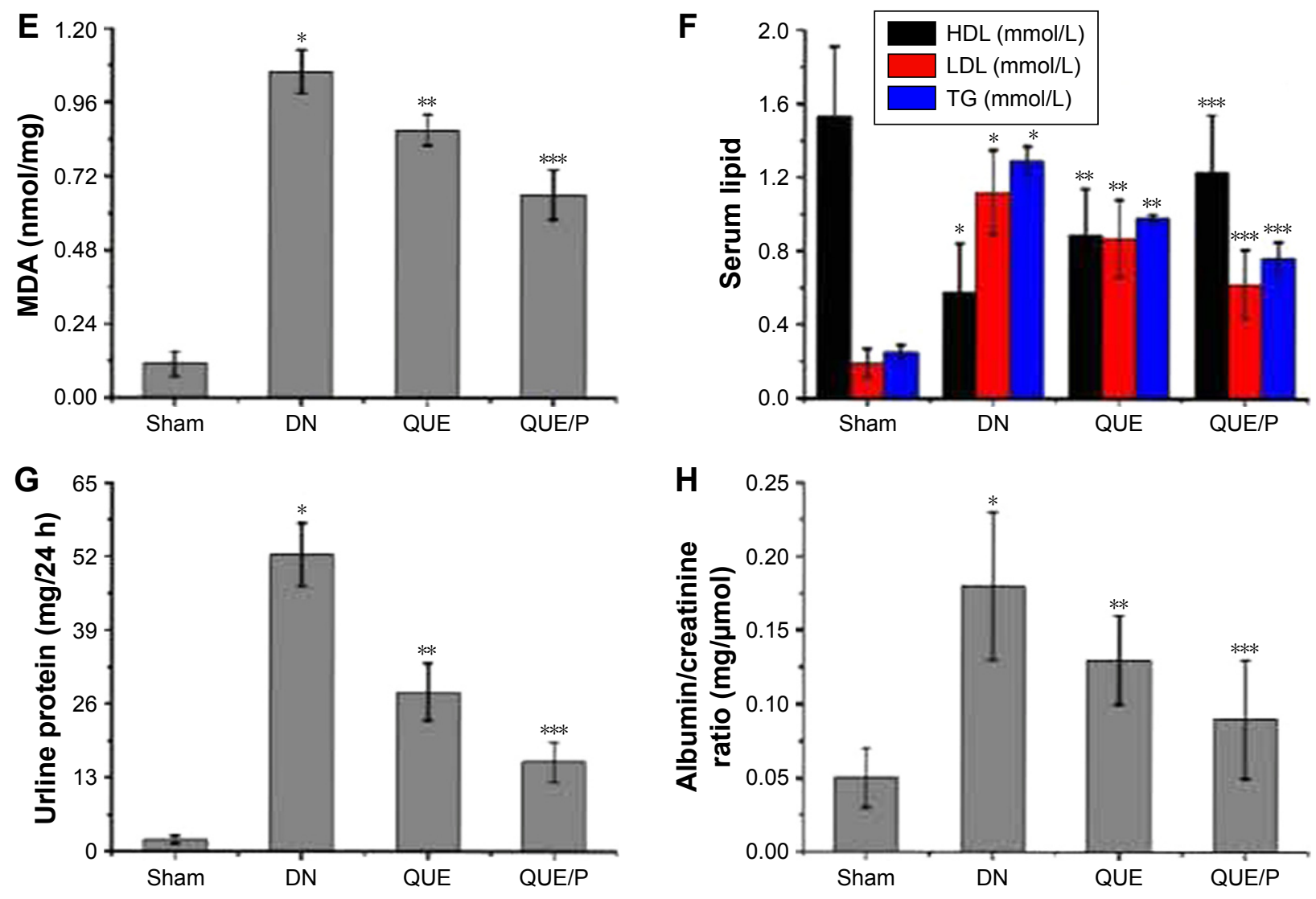

Figure 4 The activity of SOD and the levels of blood glucose, BUN, Scr, MDA, HDL, LDL, TG, urine protein, and albumin/creatinine ratio.

Notes: (A) Level of blood glucose in control group, QUE group, QUE/P group, respectively; (B) level of BUN in Sham group, DN group, QUE group, QUE/P group, respectively; (C) level of Scr in Sham group, DN group, QUE group, QUE/P group, respectively; (D) activity of SOD in Sham group, DN group, QUE group, QUE/P group, respectively; (E) level of MDA in Sham group, DN group, QUE group, QUE/P group, respectively; (F) level of HDL, LDL, and TG in Sham group, DN group, QUE group, QUE/P group, respectively; (G) level of urine protein in Sham group, DN group, QUE group, QUE/P group, respectively; (H) albumin/creatinine ratio. (B, C, E, F-LDL and TG, G, H) A remarkable augment relative to the Sham group is denoted by "**” $(p<0.0 \mathrm{I})$, a remarkable decrease relative to DN group is denoted by "***" ( $<<0.0 \mathrm{I})$, and a remarkable decrease relative to DN group is denoted by “****” $(p<0.0 \mathrm{I}) ;(\mathbf{D}, \mathbf{F}-\mathrm{HDL})$ a remarkable decrease relative to the Sham group is denoted by “*” ( $<<0.0 \mathrm{I})$, a remarkable increase relative to DN group is denoted by “**” $(p<0.0 \mathrm{I})$, and a remarkable increase relative to DN group is denoted by “****" $(p<0.0 \mathrm{I})$.

Abbreviations: SOD, superoxide dismutase; BUN, blood urea nitrogen; Scr, serum creatinine; MDA, malonyldialdehyde; HDL, high-density lipoprotein; LDL, low-density lipoprotein; TG, triglyceride; QUE/P, quercetin/poly(ethylene glycol)-b-(poly(ethylenediamine I-glutamate)-g-poly( $\varepsilon$-benzyloxycarbonyl-I-lysine)); DN, diabetic nephropathy.

\section{SOD activity and MDA level}

Activity of SOD was evaluated in DN group (Figure 4D), and was found to be lower in DN group than in Sham group ( $p<0.01$; SOD: Sham group $81.26 \pm 4.06 \mathrm{U} / \mathrm{mg}$, DN group 42.36 $\pm 3.49 \mathrm{U} / \mathrm{mg}$ ). Administration of QUE increased SOD $(51.37 \pm 3.57 \mathrm{U} / \mathrm{mg})$ compared with SOD in $\mathrm{DN}$ group $(p<0.01)$. Administration of QUE/P remarkably increased SOD $(69.84 \pm 3.02 \mathrm{U} / \mathrm{mg})$ compared with SOD in DN group $(p<0.01)$.

Level of MDA was evaluated in DN group (Figure 4E), and was found to be higher in DN group than in Sham group ( $p<0.01$; MDA: Sham group $0.11 \pm 0.04 \mathrm{nmol} / \mathrm{mg}$, DN group $1.06 \pm 0.07 \mathrm{nmol} / \mathrm{mg}$ ). Administration of QUE reduced MDA $(0.87 \pm 0.05 \mathrm{nmol} / \mathrm{mg})$ compared with MDA in $\mathrm{DN}$ group $(p<0.01)$. Administration of QUE/P remarkably reduced MDA $(0.66 \pm 0.08 \mathrm{nmol} / \mathrm{mg})$ compared with MDA in $\mathrm{DN}$ group $(p<0.01)$.

\section{Serum lipid content}

Level of high-density lipoprotein (HDL) was evaluated in DN group (Figure 4F), and was found to be lower in DN group than in Sham group ( $p<0.01$; HDL: Sham group $1.53 \pm 0.38 \mathrm{mmol} / \mathrm{L}, \mathrm{DN}$ group $0.58 \pm 0.26 \mathrm{mmol} / \mathrm{L})$. Administration of QUE increased HDL $(0.89 \pm 0.25 \mathrm{mmol} / \mathrm{L}) \mathrm{com}$ pared with HDL in DN group $(p<0.01)$. Administration of QUE/P remarkably increased HDL $(1.23 \pm 0.31 \mathrm{mmol} / \mathrm{L})$ compared with HDL in DN group $(p<0.01)$.

Level of low-density lipoprotein (LDL) was evaluated in DN group (Figure 4F), and was found to be higher in DN group than in Sham group ( $p<0.01$; LDL: Sham group $0.19 \pm 0.08 \mathrm{mmol} / \mathrm{L}, \mathrm{DN}$ group $1.12 \pm 0.23 \mathrm{mmol} / \mathrm{L})$. Administration of QUE decreased LDL $(0.87 \pm 0.21 \mathrm{mmol} / \mathrm{L}) \mathrm{com}$ pared with LDL in DN group $(p<0.01)$. Administration of QUE/P remarkably decreased LDL $(0.62 \pm 0.19 \mathrm{mmol} / \mathrm{L})$ compared with LDL in DN group $(p<0.01)$. 
Level of triglyceride (TG) was evaluated in DN group (Figure 4F), and was found to be higher in DN group than in Sham group $(p<0.01$; TG: Sham group $0.25 \pm 0.04 \mathrm{mmol} / \mathrm{L}$, $\mathrm{DN}$ group $1.29 \pm 0.08 \mathrm{mmol} / \mathrm{L})$. Administration of QUE decreased TG $(0.98 \pm 0.02 \mathrm{mmol} / \mathrm{L})$ compared with TG in DN group $(p<0.01)$. Administration of QUE/P demarkably decreased TG $(0.76 \pm 0.09 \mathrm{mmol} / \mathrm{L})$ compared with $\mathrm{TG}$ in DN group $(p<0.01)$.

\section{Urine protein}

Level of urine protein was evaluated in DN group (Figure 4G), and was found to be higher in DN group than in Sham group ( $p<0.01$; urine protein: Sham group $2.14 \pm 0.67 \mathrm{mg} / 24 \mathrm{~h}$, DN group $52.29 \pm 5.59 \mathrm{mg} / 24 \mathrm{~h}$ ). Administration of QUE decreased urine protein $(28.15 \pm 5.07 \mathrm{mg} / 24 \mathrm{~h})$ compared with urine protein in DN group $(p<0.01)$. Administration of QUE/P demarkably decreased urine protein $(15.79 \pm 3.49 \mathrm{mg} / 24 \mathrm{~h})$ compared with urine protein in DN group $(p<0.01)$.

\section{Albumin/creatinine ratio}

Level of albumin/creatinine ratio was evaluated in DN group (Figure $4 \mathrm{H}$ ), and was found to be higher in DN group than in Sham group $(p<0.01$; albumin/creatinine ratio: Sham group $0.05 \pm 0.02 \mathrm{mg} / \mu \mathrm{mol}, \mathrm{DN}$ group $0.18 \pm 0.05 \mathrm{mg} / \mu \mathrm{mol}$ ). Administration of QUE decreased albumin/creatinine ratio $(0.13 \pm 0.03 \mathrm{mg} / \mu \mathrm{mol})$ compared with albumin/creatinine ratio in DN group $(p<0.01)$. Administration of QUE/P demarkably decreased albumin/creatinine ratio $(0.09 \pm 0.04 \mathrm{mg} / \mu \mathrm{mol})$ compared with albumin/creatinine ratio in DN group $(p<0.01)$.

\section{QUE/P suppressed neutrophil adhesion}

To evaluate neutrophil adhesion in HUVECs (Figure 5). TNF- $\alpha$ stimulation remarkably enhanced leukocyte adhesion to ECs. QUE reduced leukocyte binding to TNF$\alpha$-challenged HUVECs and QUE/P remarkably reduced leukocyte binding to TNF- $\alpha$-challenged HUVECs (Figure 5). Our result affirmed that QUE or QUE/P modulated leukocyte adherence to the TNF- $\alpha$-challenged HUVECs.

\section{Expression of ICAM-I}

Expression of ICAM-1 was higher in NC group than in QUE and QUE/P groups $(p<0.01)$. Administration of QUE decreased ICAM-1 expression compared with ICAM-1 expression in NC group $(p<0.01)$. Administration of QUE/P demarkably decreased ICAM-1 expression compared with ICAM-1 expression in NC group $(p<0.01)$ (Figure 6A). Expression of ICAM-1 was higher in $\mathrm{DN}+2$ week group than in $\mathrm{DN}+1$ week group $(p<0.01)$. Expression of ICAM-1 was higher in $\mathrm{DN}+4$ week group than in $\mathrm{DN}+2$ week group $(p<0.01)$. Expression of ICAM-1 was higher in DN+8 week group than in $\mathrm{DN}+4$ week group $(p<0.01)$ (Figure 6B). Expression of ICAM-1 was higher in DN group than in Sham group $(p<0.01)$. Administration of QUE decreased ICAM-1 expression compared with ICAM-1 expression in DN group $(p<0.01)$. Administration of QUE/P demarkably decreased
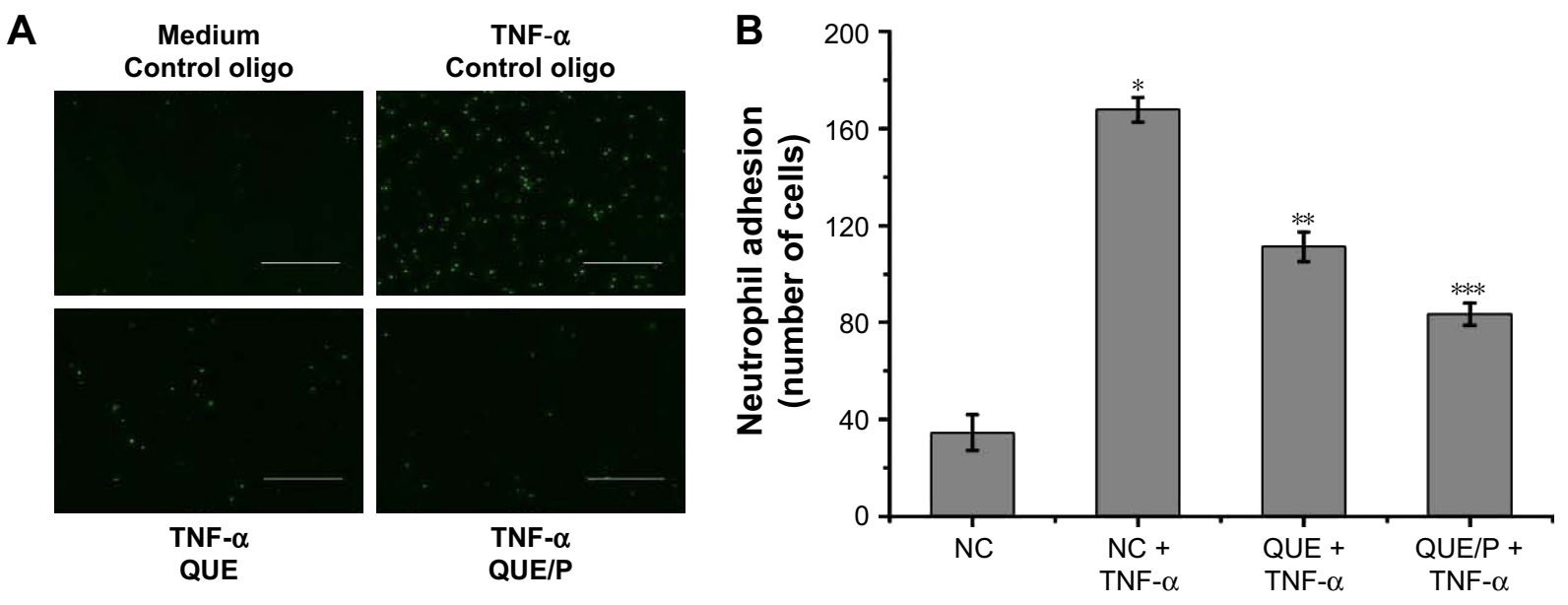

Figure 5 QUE/P inhibits neutrophil adhesion in vivo (immunofluorescence photomicrographs).

Notes: (A) The image displaying CFSE-labeled HL-60 adhesion to HUVECs. HUVECs are administrated with QUE, QUE/P, and control oligonucleotide for 24 h and then administrated with or without TNF- $\alpha$ for 6 h. CFSE-labeled HL-60 are put into the HUVECs and incubated at $37^{\circ} \mathrm{C}$ for 45 min, and then the mixtures were washed. (B) Amount of neutrophil (CFSE-labeled HL-60) adhering to HUVECs in NC group, NC + TNF- $\alpha$ group, QUE + TNF- $\alpha$ group, QUE/P + TNF- $\alpha$ group, respectively. Data are shown as mean $\pm S D$. A remarkable augment relative to the NC group is denoted by “*” $(p<0.0 \mathrm{I})$, a remarkable decrease relative to NC + TNF- $\alpha$ group is denoted by “**” $(p<0.0 \mathrm{I})$, and a remarkable decrease relative to NC + TNF- $\alpha$ group is denoted by “****” $(p<0.0 \mathrm{I})$.

Abbreviations: QUE/P, quercetin/poly(ethylene glycol)-b-(poly(ethylenediamine I-glutamate)-g-poly( $\varepsilon$-benzyloxycarbonyl-I-lysine)); CFSE, carboxyfluorescein diacetate succinimidyl ester; HL-60, acute promyelocytic leukemia; HUVECs, human umbilical vein endothelial cells; TNF- $\alpha$, tumor necrosis factor- $\alpha$; SD, standard deviation; NC, normal control. 

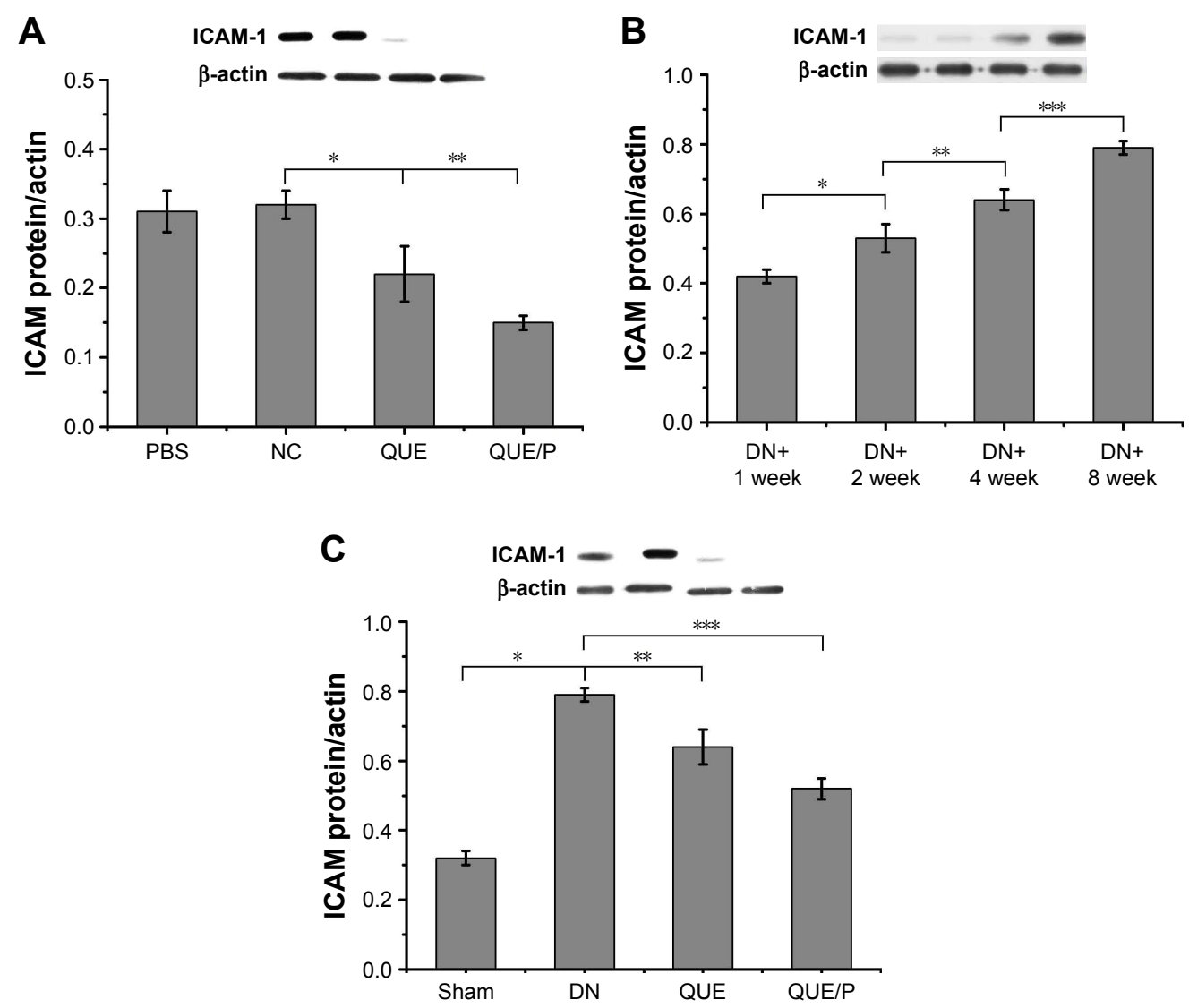

Figure 6 QUE/P downregulates ICAM-I expression in vivo.

Notes: (A) Expression of ICAM-I in PBS group, NC group, QUE group, QUE/P group, respectively. (B) Expression of ICAM-I in DN+I week group, DN+2 week group, $\mathrm{DN}+4$ week group, DN+8 week group, respectively. (C) Expression of ICAM-I in Sham group, DN group, QUE group, QUE/P group, respectively. A remarkable decrease relative to the NC group is denoted by “*” $(p<0.0 \mathrm{I})$, a remarkable decrease relative to NC group is denoted by “**” $(p<0.0 \mathrm{I})(\mathbf{A})$; a remarkable augment relative to the $\mathrm{DN}+\mathrm{I}$ week group is denoted by “*” $(p<0.0 \mathrm{I})$, a remarkable increase relative to $\mathrm{DN}+2$ week group is denoted by “*** ( $p<0.0 \mathrm{I})$, and a remarkable increase relative to $\mathrm{DN}+4$ week group is denoted by “****” $(p<0.0 \mathrm{I})(\mathrm{B})$; a remarkable augment relative to the DN group is denoted by “*” ( $p<0.0 \mathrm{I})$, a remarkable decrease relative to DN group is denoted by “***" $(p<0.0 \mathrm{I})$, and a remarkable decrease relative to DN group is denoted by “****" $(p<0.0 \mathrm{I})(\mathbf{C})$.

Abbreviations: QUE/P, quercetin/poly(ethylene glycol)-b-(poly(ethylenediamine I-glutamate)-g-poly(E-benzyloxycarbonyl-I-lysine)); ICAM-I, intercellular adhesion molecular-I; PBS, phosphate-buffered saline; DN, diabetic nephropathy; NC, normal control.

ICAM-1 expression compared with ICAM-1 expression in DN group $(p<0.01)$ (Figure 6C).

\section{QUE/P attenuated inflammatory cells infiltration to the kidney tissue following DN}

Infiltration of $\mathrm{CD} 11 \mathrm{~b}^{+}$was evaluated in NC-DN group (Figure 7). Administration of QUE decreased CD11 b ${ }^{+}$infiltration compared with $\mathrm{CD} 11 \mathrm{~b}^{+}$infiltration in NC-DN group $(p<0.01)$. Administration of QUE/P demarkably decreased $\mathrm{CD} 11 \mathrm{~b}^{+}$infiltration compared with $\mathrm{CD} 11 \mathrm{~b}^{+}$infiltration in NC-DN group $(p<0.01)$.

\section{Discussion}

Diabetes mellitus contributed to pathology in a wide change of conditions, containing large vessels and microvascular damage, and was also a major challenge during heart, brain, peripheral nerves, eyes, feet and kidney injury. In this study, diabetes mellitus involved in kidney damage was a life-threatening complication. ${ }^{37}$ Currently, innovative curative methods for DN make use of traditional antidiabetic drugs (such as insulin and exenatide), metabolic modulation, cell factors, therapeutic gases like hydrogen sulfide, nucleotide, and QUE. ${ }^{10,38-44}$ QUE belongs to plant flavonoid and modulates oxidative stress and inflammatory injury in vivo. ${ }^{12}$ A growing number of researches have suggested that QUE is involved in the modulation of DN. ${ }^{44}$ However, since QUE possesses the shortcoming of low solubility and short circulation time in vivo, we therefore synthesized PEG$b$-(PELG-g-PZLL) carrier to load QUE through hydrophobic interaction for improving its bioactivity in vivo. In this research, PEG- $b$-(PELG- $g$-PZLL) really promoted the therapeutic effect of QUE in DN. In the rat model of DN, QUE or QUE/P ameliorated renal pathological damage, enhanced 
A

\section{B}

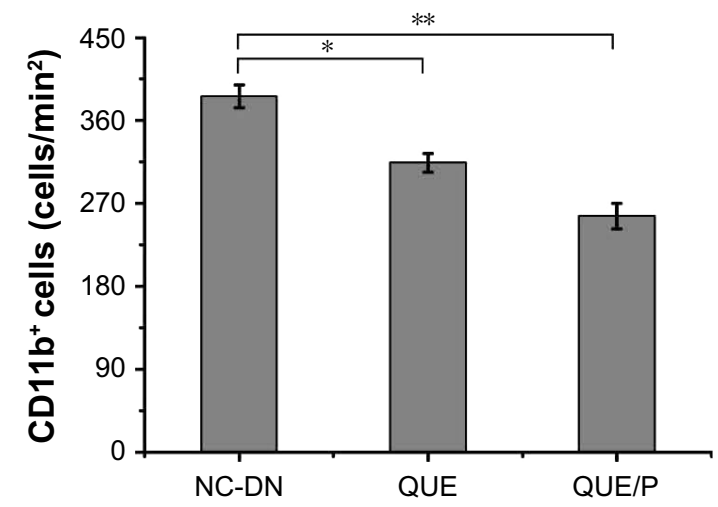

Figure 7 QUE/P decreases inflammatory cell infiltration to the DN. Notes: (A) Image of immunohistochemical staining for $\mathrm{CDI}^{\mathrm{l} \mathrm{b}^{+}}$myeloid cells in NC-DN group, QUE group, QUE/P group, respectively; (B) quantitative value in NC-DN group, QUE group, QUE/P group, respectively. A remarkable decrease relative to the NC-DN group is denoted by “*” $(p<0.0 \mathrm{I})$ and a remarkable decrease relative to NC-DN group is denoted by “**” $(p<0.0 \mathrm{I})$.

Abbreviations: QUE/P, quercetin/poly(ethylene glycol)-b-(poly(ethylenediamine Iglutamate)-g-poly(ع-benzyloxycarbonyl-I-lysine)); DN, diabetic nephropathy; NC, normal control.

renal function recovery, promoted metabolic modulation, and alleviated oxidative stress and inflammatory injury.

The extensive change of pathological procedure contributed to DN, within which leukocyte-EC adhesion and EC inflammation exacerbated glomerular EC injury. ${ }^{45-49}$ Hence, reducing leukocyte-EC adhesion and EC inflammation are promising therapeutic tactics to alleviate DN. ICAM-1 is a member of the CAM superfamily and plays an important effect in mediating the migration of leukocytes to pass through the endothelium and enter the kidneys. In the current study, a wide range of pathological process contributed to $\mathrm{DN}$, among which leukocyte-EC adhesion and EC inflammation exacerbated renal dysfunction in DN. There was a growing appreciation that ECs were vulnerable to DN and they could be the critical determinants for the extent of DN and the recovery time. Consequently, reducing microvascular permeability and restraining leukocyte-EC adhesion improved therapeutic effects to decrease DN. ICAM-1, a member of cells adhesion molecule superfamily expressed via ECs, played a important function in mediating the migration of leukocyte across the endothelium and into the kidney. QUE or QUE/P ameliorated leukocyte-EC adhesion and EC inflammation through modulating ICAM-1 expression. On the other hand, TNF- $\alpha$-stimulated HUVEC was regarded as a model of EC inflammation, and QUE or QUE/P downregulated EC inflammation in TNF- $\alpha$-stimulated
HUVECs. The result showed that QUE or QUE/P decreased leukocyte-EC adhesion and EC inflammation to ameliorate tissue injury. Moreover, in vivo research using DN model affirmed that QUE or QUE/P restrained the enhancement of $\mathrm{CD} 11 \mathrm{~b}^{+}$myeloid cells in DN. The findings showed that QUE or QUE/P attenuated DN through suppressing ICAM-1 expression and inflammatory cell infiltration $\left(\mathrm{CD} 11 \mathrm{~b}^{+}\right)$. These results were consistent with previous documents. ${ }^{50-53}$ Furthermore, in vivo study using DN model showed that QUE or QUE/P suppressed expression of ICAM-1, thereby decreasing the accumulation of $\mathrm{CD} 11 \mathrm{~b}^{+}$myeloid cells in the $\mathrm{DN}$, which may account for the decreased DN as evidenced by decreased MDA level and increased SOD activity.

In conclusion, we found that PEG- $b$-(PELG- $g$-PZLL) could improve the serum content of QUE in Sprague Dawley rats and increase the circulation time of QUE. In addition, PEG- $b$-(PELG-g-PZLL) could maintain a normal glucose level for up to 5 days, compared to free QUE in diabetic rats, and remarkably alleviate DN through suppressing ICAM-1 expression. These researches amplified our understanding of the interaction between QUE or QUE/P and ECs and its effect in DN. Hence, QUE or QUE/P may act as a valuable therapeutic drug in the setting of DN.

\section{Conclusion}

Synthesized PEG- $b$-(PELG-g-PZLL) remarkably augmented the bioactivity of QUE. Administration of QUE/P remarkably improved the serum content of QUE in Sprague Dawley rats, and also remarkably inhibited the hyperglycemia and decreased DN.

\section{Acknowledgment}

The authors appreciated the support from the Science and Technology Planning Project of Jiaxing (2017AY33076).

\section{Disclosure}

The authors report no conflicts of interest in this work.

\section{References}

1. Andersen AR, Christiansen JS, Andersen JK, Kreiner S, Deckert T. Diabetic nephropathy in Type 1 (insulin-dependent) diabetes: an epidemiological study. Diabetologia. 1983;25(6):496-501.

2. Rossing P, Rossing K, Jacobsen P, Parving HH. Unchanged incidence of diabetic nephropathy in IDDM patients. Diabetes. 1995;44(7): 739-743.

3. Anjaneyulu M, Chopra K. Quercetin, an anti-oxidant bioflavonoid, attenuates diabetic nephropathy in rats. Clin Exp Pharmacol Physiol. 2004;31(4):244-248.

4. Lin CY, Yin MC. Renal protective effects of extracts from guava fruit (Psidium guajava L.) in diabetic mice. Plant Foods Hum Nutr. 2012; 67(3):303-308. 
5. Aires Neto P, Gomes HV, Campos M. Management of hyperglycemia in patients with chronic kidney disease. J Nephrol. 2013;26(4): $629-635$.

6. Vallon V, Rose M, Gerasimova M, et al. Knockout of Na-glucose transporter SGLT2 attenuates hyperglycemia and glomerular hyperfiltration but not kidney growth or injury in diabetes mellitus. $\mathrm{Am} \mathrm{J}$ Physiol Renal Physiol. 2013;304(2):F156-F167.

7. Powell DW, Kenagy DN, Zheng S, et al. Associations between structural and functional changes to the kidney in diabetic humans and mice. Life Sci. 2013;93(7):257-264.

8. Hong JN, Li WW, Wang LL, et al. Jiangtang decoction ameliorate diabetic nephropathy through the regulation of PI3K/Akt-mediated NF-кB pathways in KK-Ay mice. Chin Med. 2017;12:13.

9. Gomes IB, Porto ML, Santos MC, et al. Renoprotective, anti-oxidative and anti-apoptotic effects of oral low-dose quercetin in the C57BL/6J model of diabetic nephropathy. Lipids Health Dis. 2014;13:184.

10. Tong F. Preparation of exenatide-loaded linear poly(ethylene glycol)brush poly(l-lysine) block copolymer: potential implications on diabetic nephropathy. Int J Nanomedicine. 2017;12:4663-4678.

11. Brownlee M. Biochemistry and molecular cell biology of diabetic complications. Nature. 2001;414(6865):813-820.

12. Stewart LK, Soileau JL, Ribnicky D, et al. Quercetin transiently increases energy expenditure but persistently decreases circulating markers of inflammation in C57BL/6J mice fed a high-fat diet. Metabolism. 2008;57(7 Suppl 1):S39-S46.

13. Xie W, Du L. Diabetes is an inflammatory disease: evidence from traditional Chinese medicines. Diabetes Obes Metab. 2011;13(4): 289-301.

14. Csokay B, Prajda N, Weber G, Olah E. Molecular mechanisms in the antiproliferative action of quercetin. Life Sci. 1997;60(24): 2157-2163

15. Lou M, Zhang LN, Ji PG, et al. Quercetin nanoparticles induced autophagy and apoptosis through AKT/ERK/Caspase-3 signaling pathway in human neuroglioma cells: in vitro and in vivo. Biomed Pharmacother. 2016;84:1-9.

16. Wu XM, Gao YB, Xu LP, et al. Tongxinluo inhibits renal fibrosis in diabetic nephropathy: involvement of the suppression of intercellular transfer of TGF-[formula: see text]1-containing exosomes from GECs to GMCs. Am J Chin Med. 2017;45(5):1075-1092.

17. Wang ZB, Zhang S, Li Y, et al. LY333531, a PKC $\beta$ inhibitor, attenuates glomerular endothelial cell apoptosis in the early stage of mouse diabetic nephropathy via down-regulating swiprosin-1. Acta Pharmacol Sin. 2017;38(7):1009-1023.

18. Davidson SM, Duchen MR. Endothelial mitochondria: contributing to vascular function and disease. Circ Res. 2007;100(8):1128-1141.

19. Kharbanda RK, Peters M, Walton B, et al. Ischemic preconditioning prevents endothelial injury and systemic neutrophil activation during ischemia-reperfusion in humans in vivo. Circulation. 2001;103(12): 1624-1630

20. Yamagata K, Tagami M, Yamori Y. Dietary polyphenols regulate endothelial function and prevent cardiovascular disease. Nutrition. 2015; 31(1):28-37.

21. Rebholz CM, Harman JL, Grams ME, et al. Association between Endothelin-1 Levels and Kidney Disease among Blacks. J Am Soc Nephrol. Epub 2017 Jul 11.

22. Hara T, Ishida T, Cangara HM, Hirata K. Endothelial cell-selective adhesion molecule regulates albuminuria in diabetic nephropathy. Microvasc Res. 2009;77(3):348-355.

23. Sugimoto H, Shikata K, Hirata K, et al. Increased expression of intercellular adhesion molecule-1 (ICAM-1) in diabetic rat glomeruli: glomerular hyperfiltration is a potential mechanism of ICAM-1 upregulation. Diabetes. 1997;46(12):2075-2081.

24. Li Z, Yang Z, Luo X, et al. Effects of burn serum on expression of CD11/CD18 on polymorphonuclear neutrophils and ICAM-1 on endothelial cells. Acta Academiae Medicinae Militaris Tertiae. 1997;19: 101-104.
25. Liu RR, Li J, Gong JY, et al. MicroRNA-141 regulates the expression level of ICAM-1 on endothelium to decrease myocardial ischemia-reperfusion injury. Am J Physiol Heart Circ Physiol. 2015;309(8):H1303-H1313.

26. Behr J, Gaskin B, Fu C, Dong C, Kunz R. Localized modeling of biochemical and flow interactions during cancer cell adhesion. PLoS One. 2015;10(9):e0136926

27. Tian S, Tang J, Liu H, et al. Propyl gallate plays a nephroprotective role in early stage of diabetic nephropathy associated with suppression of glomerular endothelial cell proliferation and angiogenesis. Exp Diabetes Res. 2012;2012:209567.

28. Sugimoto H, Shikata K, Matsuda M, et al. Increased expression of endothelial cell nitric oxide synthase (ecNOS) in afferent and glomerular endothelial cells is involved in glomerular hyperfiltration of diabetic nephropathy. Diabetologia. 1998;41(12):1426-1434.

29. Lu Q, Ji XJ, Zhou YX, et al. Quercetin inhibits the mTORC1/p70S6K signaling-mediated renal tubular epithelial-mesenchymal transition and renal fibrosis in diabetic nephropathy. Pharmacol Res. 2015;99: 237-247.

30. Li C, Zhang WJ, Frei B. Quercetin inhibits LPS-induced adhesion molecule expression and oxidant production in human aortic endothelial cells by p38-mediated Nrf2 activation and antioxidant enzyme induction. Redox Biol. 2016;9:104-113.

31. Bhaskar S, Sudhakaran PR, Helen A. Quercetin attenuates atherosclerotic inflammation and adhesion molecule expression by modulating TLR-NF-אB signaling pathway. Cell Immunol. 2016;310:131-140.

32. Chakraborty J, Singh R, Dutta D, Naskar A, Rajamma U, MohanakumarKP. Quercetin improves behavioral deficiencies, restores astrocytes and microglia, and reduces serotonin metabolism in 3-nitropropionic acidinduced rat model of Huntington's Disease. CNS Neurosci Ther. 2014; 20(1):10-19.

33. Tong F, Tang X, Li X, Xia W, Liu D. The effect of insulin-loaded linear poly(ethylene glycol)-brush-like poly(1-lysine) block copolymer on renal ischemia/reperfusion-induced lung injury through downregulating hypoxia-inducible factor. Int J Nanomedicine. 2016;11:1717-1730.

34. Feng XZ, Ding YF, Li X, et al. HPLC determination of quercetin and its entrapment efficiency in nanoliposome. Chin J Pharm Anal. 2008; 28(4):556-558.

35. Li S, Jiang WQ, Wang AX, Guan ZZ, Zhang L, Pan SR. Releasing characterization, pharmacokinetics and distribution of PEG-PBLG copolymer micelles in vitro and in vivo. Chinese Pharm J. 2005;40(9):699-702.

36. Ding Y, Vaziri ND, Coulson R, Kamanna VS, Roh DD. Effects of simulated hyperglycemia, insulin, and glucagon on endothelial nitric oxide synthase expression. Am J Physiol Endocrinol Metab. 2000;279(1): E11-E17.

37. Abouzed TK, Munesue S, Harashima A, et al. Preventive effect of salicylate and pyridoxamine on diabetic nephropathy. J Diabetes Res. 2016;2016:1786789.

38. Safar MM, Abdelsalam RM. H2S donors attenuate diabetic nephropathy in rats: modulation of oxidant status and polyol pathway. Pharmacol Rep. 2015;67(1):17-23.

39. Zhang Y, Jia N, Hu F, et al. Association of single-nucleotide polymorphisms in the RAGE gene and its gene-environment interactions with diabetic nephropathy in Chinese patients with type 2 diabetes. Oncotarget. Epub 2017 Jun 28.

40. Dhamodharan U, Ezhilarasi K, Ponjayanthi B, Sireesh D, Ramkumar KM, Viswanathan V. Association of A1538G and C2437T single nucleotide polymorphisms in heat shock protein-70 genes with diabetic nephropathy among South Indian population. Biosci Rep. 2017;37(2). pii: BSR20160605.

41. Tian W, Chen L, Zhang L, et al. Effects of ginsenoside Rg1 on glucose metabolism and liver injury in streptozotocin-induced type 2 diabetic rats. Genet Mol Res. 2017;16(1).

42. Ngubane PS, Hadebe SI, Serumula MR, Musabayane CT. The effects of transdermal insulin treatment of streptozotocin-induced diabetic rats on kidney function and renal expression of glucose transporters. Ren Fail. 2015;37(1):151-159. 
43. Siddiqi FS, Chen LH, Advani SL, et al. CXCR4 promotes renal tubular cell survival in male diabetic rats: implications for ligand inactivation in the human kidney. Endocrinology. 2015;156(3):1121-1132.

44. Gomes IB, Porto ML, Santos MC, et al. The protective effects of oral low-dose quercetin on diabetic nephropathy in hypercholesterolemic mice. Front Physiol. 2015;6:247.

45. Bonventre JV, Yang L. Cellular pathophysiology of ischemic acute kidney injury. J Clin Invest. 2011;121(11):4210-4221.

46. Rops AL, Jacobs CW, Linssen PC, et al. Heparan sulfate on activated glomerular endothelial cells and exogenous heparinoids influence the rolling and adhesion of leucocytes. Nephrol Dial Transplant. 2007;22(4): 1070-1077.

47. Yasuda M, Ohbayashi M, Shimizu S, Yamamoto T. Angiogenesis induced by adhesion between polymorphonuclear leukocyte and endothelial cell via intercellular adhesion molecule-1. New Frontiers in Regenerative Medicine. 2007:83-93. (Conference paper)

48. Xu G, Qin Q, Yang M, Qiao Z, Gu Y, Niu J. Heparanase-driven inflammation from the AGEs-stimulated macrophages changes the functions of glomerular endothelial cells. Diabetes Res Clin Pract. 2017; $124: 30-40$
49. Yin QH, Zhang R, Li L, et al. Exendin-4 ameliorates lipotoxicityinduced glomerular endothelial cell injury by improving ABC transporter A1-mediated cholesterol efflux in diabetic apoE knockout mice. J Biol Chem. 2016;291(51):26487-26501.

50. Høj Thomsen L, Fog-Tonnesen M, Nielsen Fink L, et al. Smad2 phosphorylation in diabetic kidney tubule epithelial cells is associated with modulation of several transforming growth factor- $\beta$ family members. Nephron. 2017;135(4):291-306.

51. Namgung S, Yoon JJ, Yoon CS, et al. Prunella vulgaris attenuates diabetic renal injury by suppressing glomerular fibrosis and inflammation. Am J Chin Med. 2017;45(3):475-495.

52. Yu CS, Lai KC, Yang JS, et al. Quercetin inhibited murine leukemia WEHI-3 cells in vivo and promoted immune response. Phytother Res. 2010;24(2):163-168.

53. Kobuchi H, Roy S, Sen CK, Nguyen HG, Packer L. Quercetin inhibits inducible ICAM-1 expression in human endothelial cells through the JNK pathway. Am J Physiol. 1999;277(3 Pt 1):C403-C411. 


\section{Supplementary materials} Synthesis of PEG-b-(PELG-g-PZLL)

Poly(ethylene glycol)- $b$-(poly(ethylenediamine l-glutamate)$g$-poly( $\varepsilon$-benzyloxycarbonyl-1-lysine)) (PEG- $b$-(PELG$g$-PZLL)) was synthesized by the following method: PEG- $b$-PBLG was prepared via ring-opening polymerization of BLG-N-carboxyanhydride (NCA), with PEG$\mathrm{NH}_{2}$ as the macroinitiator, followed via aminolysis with ethanediamine to get PEG- $b$-PELG. PEG- $b$-PELG was used as the macroinitiator to initiate the ring-opening polymerization of ZLL-NCA to obtain PEG- $b$-(PELG- $g$-PZLL), as depicted in Figure S1. The degree of polymerization of PELG was 50 and the degree of polymerization of PZLL was 3 , and they were characterized via ${ }^{1} \mathrm{H}$-nuclear magnetic resonance and gel permeation chromatogram, as depicted in Figure S2.

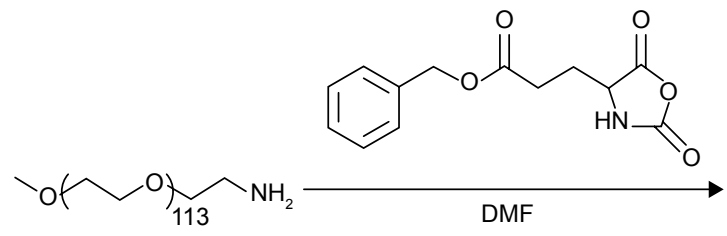

PEG-NH

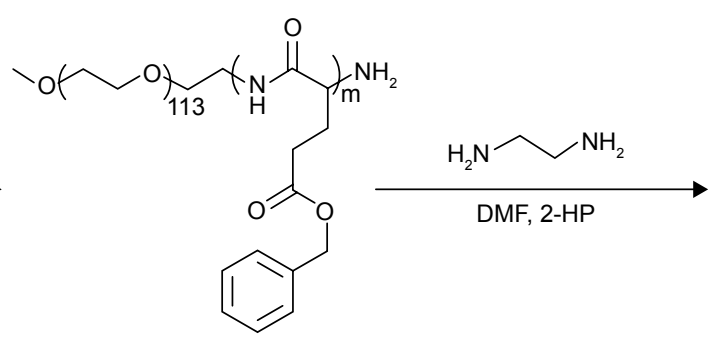

PEG-b-PBLG<smiles>COCCOCC(C)NC(=O)C(N)CCC(=O)NCCN</smiles>

PEG-b-PELG

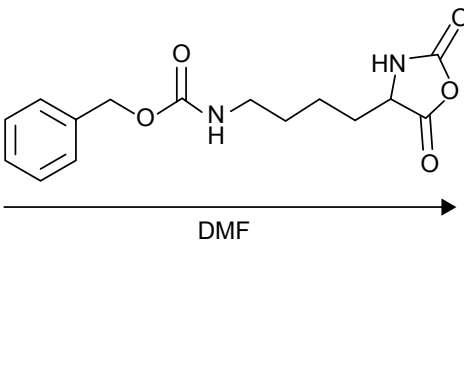

PEG-b-(PELG-g-PZLL)

Figure SI Synthesis of PEG-b-(PELG-g-PZLL).

Abbreviations: PEG-NH , poly(ethylene glycol) amine; PEG-b-PBLG, poly(ethylene glycol)-b-poly( $\gamma$-benzyl l-glutamate); PEG-b-PELG, poly(ethylene glycol)-b-poly(ethylenediamine I-glutamate); PEG-b-(PELG-g-PZLL), poly(ethylene glycol)-b-(poly(ethylenediamine l-glutamate)-g-poly(E-benzyloxycarbonyl-I-lysine)). 

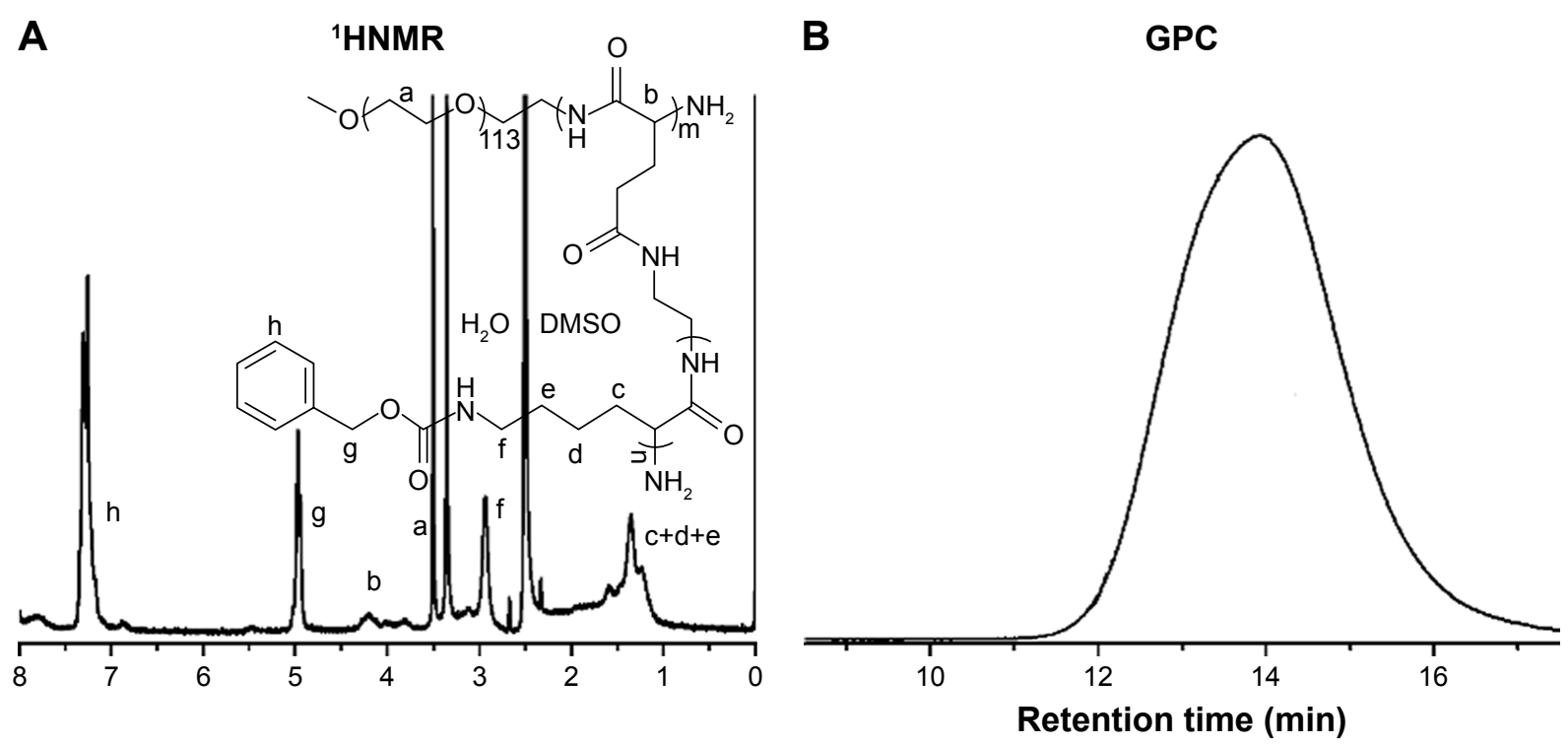

Figure S2 Characterization of PEG-b-(PELG-g-PZLL).

Notes: (A) 'HNMR of PEG-b-(PELG-g-PZLL ); (B) GPCs of PEG-b-(PELG-g-PZLL).

Abbreviations: PEG-b-(PELG-g-PZLL), poly(ethylene glycol)-b-(poly(ethylenediamine I-glutamate)-g-poly(E-benzyloxycarbonyl-I-lysine)); 'HNMR, 'H-nuclear magnetic resonance; GPC, gel permeation chromatogram.

\section{Publish your work in this journal}

The International Journal of Nanomedicine is an international, peerreviewed journal focusing on the application of nanotechnology in diagnostics, therapeutics, and drug delivery systems throughou the biomedical field. This journal is indexed on PubMed Central, MedLine, CAS, SciSearch $®$, Current Contents $\AA /$ Clinical Medicine,
Journal Citation Reports/Science Edition, EMBase, Scopus and the Elsevier Bibliographic databases. The manuscript management system is completely online and includes a very quick and fair peer-review system, which is all easy to use. Visit http://www.dovepress.com/ testimonials.php to read real quotes from published authors. 